blood, followed by hyperæmia, is quite incapable of explaning the phenomena of the disease, and that changes originating in the cells of the derma and rete mucosum have most to do therewith. Modern research seems to point to an altered relation between the nerve-force and the cell-life as the starting point or the reason why eczema occurs; for nerve irritation certainly can give rise to cell proliferation, and it seems clear that nerve filaments run to, and lose themselves in, the rete where the changes in eczema are the most marked. Well, given " perverted innervation," as Hebra terms it, we can readily see how agencies, acting both externally and internally, can excite, evoke, or-not per se-cause eczema; how eczema can be modified by altered blood-states or constitutional tendencies, such as gout or struma ; but, further, we do not explain the hereditary transmission of eczema by regarding it as a blood disease. The influence of organic or functional diseases of important organs is a matter requiring to be more distinctly appreciated, in so far as they throw more work upon the skin, lead to debility, or the impurification of the blood-current. The mucous and cutaneous membranes exhibit, it would appear, a remarkable similarity in regard to the essential pathological changes that take place in catarrh, on the one hand, and eczema on the other; so much so as to lead one to suppose-allowing for difference of texture and accidental surroundings, such as heat, moisture, and exposure to the external air-that the two above mentioned are analogous affections. This is the more probable on a consideration of their now and then decidedly "substitutive" correlation. Speaking in broad terms, we should say, moreover, that the cause of eczema is multiple ; it is perverted innervation as a sine $q u \hat{a}$ non, but plus-not as causes, but part causes or excitants in variety of combinations and varying frequency of coexistence-general debility, morbid blood-states, strumous diathesis, local irritation of the most diverse kinds, disease of important viscera, mental depression, and so on. I repeat that the dermatologist must comprehend the nature of diseases in general ere he can treat skin diseases successfully.

Finally, I would remind you that the foregoing remarks refer to what is essentially eczema in its three varieties, each with its stages of erythema, papulation, vesiculation, pustulation, discharge, and squamation. There are certain secondary and accidental changes that we must not lose sight of-changes that are common to every form of chronic inflammation-namely, induration, atrophy, ulceration, and the like. Varieties have been made according to the varying aspect of these accidental and secondary changes; hence the terms Eczema odematosum, verrucosum, sclerosum, \&c. But surely in such cases the eczema has practically given place to what surgeons term " chronic inflammation," which reaches its highest development in the so-called "elephantiasis of the leg," or, more properly, spargosis. I said in my first lecture that dermatologists often take mere accidental features as sufficient to form varieties, and altogether fail to be guided by the only correct principle-namely, the formation of varieties only by a consideration of the whole course of diserses, and the more prominent and special features presented by them at their height of development.

This outline of the pathology and etiology of eczema seems to me to give the clue to a satisfactory plan of treatment for the disease; and no one can accuse me, I trust, in my dealing with the question, of being the mere specialist.

\section{SUDDEN DEATH IN OVARIOTOMY WHIIST THE PATIENT WAS UNDER THE IN FLUENCE OF CHLOROFORM.}

\section{By SiR J. Y. SIMPSON, BART., M.D., D.C.L. PROFESEOR OF MEDICINE AND MIDWIFERY IN THE UNIVERSITY OF EDINBCRGE.}

A FEW weeks ago Dr. Brotherstone, of Alloa, sent into Edinburgh a patient who was the subject of an ovarian tumour. She brought a note from him asking if $I$ thought the case a fit one for ovariotomy. I wrote back that it seemed to me to be so. The patient was married, about twenty-two years of age, thin and emaciated, and I thought the tumour, which was as large as the pregnant uterus at the sixth or seventh month, felt more solid than multilocular ovarian tumours of this size usually do, yet it seemed free from adhesions.

Dr. Brotherstone took the patient in to the small Village Hospital at Alloa, and urgently requested me to be present when he operated. Accordingly, on the morning of the 5th of February I went up to him. Drs. Duncanson and Wilson, of Alloa, were also to be present; but Dr. Duncanson did not arrive till after the patient was laid upon the table, and the operation begun. With the view of allowing Dr. Wilson to give full assistance to Dr. Brotherstone at the operation, I chloroformed the patient. In doing so I placed a single layer of towel over the nose and mouth, leaving the eyes exposed, and dropped the chloroform upon the towel. When Dr. Brotherstone made his first cutaneous incision, the patient moved so much that he stopped for a brief time till I put the patient more deeply under the effects of the chloroform. The tumour was rapidly reached, and was then attempted to be diminished in size by tapping; but only a comparatively small quantity of fluid escaped. Dr. Brotherstone then extended the opening upwards for an inch or more above the umbilicus, and was introducing and using his hand with the view of turning out the ovarian mass, when the patient vomited suddenly and profusely. Immediately the eyes opened, the pupils were preternaturally dilated, the face looked pallid, and the respiration, which had never been affected by the chloroform so as to have the least noise or stertor in it, seemed arrested. Instantly artificial respiration was set on foot, and the tongue pulled forward. Deep spontaneous respiration then occurred several times in succession, and I deemed at the moment that the patient was hence out of danger ; but a second collapse occurred, which terminated in death, all means of resuscitation proving unavailing.

On a post-mortem examination of the body, ordered by the legal authorities, no diseased conditions could be found in the head, chest, or elsewhere. The ovarian tumour was free from any peritoneal adhesions. On examining its structure, Dr. Pettigrew, the esteemed pathologist of the Royal Infirmary of Edinburgh, found it to be cancerous in its character.

\section{REMARKS.}

Cases of Sudden Death during Surgical Operations without Ancesthetics.

In the first paper which I published on Chloroform in the Edinburgh Monthly Journal of Medical Science for December, 1817 , I stated that this drug, if given in too great or too long-continued doses, "would doubtless produce serious consequences, and even death"; and at the same time I expressed the hope that "its great potency would be one great safeguard against its abuse." Since that period I have exhibited it myself, or been present when it was exhibited, in several thousands of instances; but have not seen its employment terminate in death before the occurrence of the preceding unhappy case.

According to all the experimental and clinical observations which have been made, chloroform appears capable of destroying life in two ways-namely, (1) by asphyxia, and (2) by syncope. Death by asphyxia can generally, if not always, be averted by at once arresting the inhalation of the drug whenever the breathing becomes noisy or stertorous, - states which, as already mentioned, never occurred with the preceding patient. Death by syncope, or sudden stoppage of the action of the heart, is, doubtlessly, far less under control, and has apparently formed the principal cause of the fatal issues in almost all the cases in which patients have perished when under the use of chloroform. Perhaps fewer cases of syncope actually occur under operations since the introduction of anæsthetics, because the nervous and sensory systems of the patients are so far obtunded by their employment; but a patient is, I believe, in greater jeopardy, if syncope do once occur, when he is under the influence of chloroform than when he is not under it, because the irritability and action of the heart are diminished by the free use of it, as shown by the lowering. and slowing of the pulse. Yet, when syncope does occur in chloroformed persons, artificial respiration and its accompaniments usually are sufficient to rally and restore the patient. When the preceding case was described by me at a late meeting of the Edinburgh Obstetrical Society, Dr. Gordon and Dr. Angus Macdonald each mentioned an in. 
stance in which sudden fainting occurred, with pallor of the face, open eyes, and very dilated pupils, at the first commencement of the incisions in two slight operations, the one for the removal of a small tumour, the other for the incision of a carbuncle; and in neither case had the patient taken any unusual dose of chloroform. They both recovered under artificial respiration.

But are all such cases of syncope which take place during operations, and which end or do not end in death, the result of the action of the chloroform which happens to be used at the time? The question is one which has never, perhaps, sufficiently attracted the attention of the profession. For doubtless it is true that antecedently to the introduction of anæsthetics patients sometimes died from syncope upon the operating table, both immediately before and after the operation was commenced, and under conditions and circumstances which in modern times, when anæsthetics are almost universally employed in operations, would be not unnaturally described and regarded as deaths from chloroform. Formerly such sudden deaths under surgical operations do not seem to have been looked upon as matters of moment, because, in fact, no special pathological or practical interest was attached to their occurrence. They were simply regarded as inevitable accidents, and are usually only incidentally alluded to, when alluded to at all, by surgical authors, provided they illustrate some special observation or opinion on the part of the writer. Thus, as showing how "violence alone, without the loss of blood, may often produce immediate fatal effects," John Hunter makes the following observation :-

CASE 1. - "I have seen," writes Mr. Hunter, "a man thrown into such convulsions from the operation of the hydrocele being performed upon him that I began to despair of his recovery. I have known," he adds, " " man die immediately of castration."' (See his Works, vol. iii., p. 431.)

In the first volume of his work on Constitutional Irritation, Mr. Travers cites several cases of sudden death in surgical patients to illustrate different pathological principles to which he points. For example, he gives the following:-

CASE 2.-A robust middle-aged man, the subject of a moderate-sized aneurism in the femoral artery, was received into the London Hospital, and readily assented to the usual operation for that disease. On entering the theatre, however, he fainted, and had some wine-and-water given to him. The operation was then proceeded with. The artery was exposed, and the ligature applied, but not tightened. During the operation it was observed that no pulsation could be felt in the tumour; and on examining the patient more minutely it was found that he was quite dead. On dissection, both sides of the heart were found empty, and the lungs turgid with blood. No other particular appearance was observable.

CASE 3.- "I saw," again writes Mr. Travers, "a man who was the subject of strangulated hernia. He expired suddenly on the table during the steps preliminary to the operation, which, from the state of the symptoms, and of the bowel as ascertained by examination after death, might be said to afford the fairest prospect of relief."

CASE 4.-A man who had been bitten in the finger by a cat, and in whom symptoms resembling those of hydrophobia had been present for twelve hours, submitted to the excision of the bitten part, and died in three minutes.

CASE 5.-A brewer's servant, a man of middle age, and robust frame, suffered much agony for several days from a thecal abscess occasioned by a splinter of wood penetrating beneath the nail of the thumb. A few seconds after the matter was discharged by a deep incision, he raised himself by a convulsive effort from his bed, and instantly expired.
(See Travers on "Constitutional Irritation," vol. i., p. 20.)

These several cases are, as I have said, stated by Mr. Travers, each to illustrate some special pathological principle, but they do not necessarily include all the cases of sudden death upon the operating table which he may have seen or heard of, and which were not calculated in his opinion to point to any special surgical fact. In former years, in talking with surgeons who had seen many operations, before the time of anæsthetics, I heard of various instances in which patients had been removed dead from the operating table; and on one oceasion, when conversing with two provincial surgeons on the subject, each after a time recalled to memory two cases, or four in all, in which they had seen surgical patients suddenly die under the surgeon's knife, years before the employment of inhaled anxsthetics. It is, perhaps, impossible now to collect adequate data to fix the probable frequency with which such accidents formerly happened. We may, probably, fairly infer, however, that they were not very rare, for, when attending specially to this question in the first years of anwsthesia in surgery, the following cases occurred in Edinburgh and its neighbourhood. CASE 6.- Shortly before the introduction of anæsthetics in surgical practice in 1846, my late friend Dr. John Argyll Robertson, lecturer on surgery, was told to see a case of strangulated inguinal hernia in the practice of Dr. Thomson. The gentleman was removed from bed, and placed upon a table to facilitate the required operation. Dr. Robertson, before proceeding to use his scalpel, was employed in removing the hairs from the groin with a razor, when the patient suddenly complained of faintness, gasped, and died.

CASE 7.-After discovering the anæsthetic effects of chloroform in November, 1847, I tested it in a case of toothpulling; but required to wait eight days before I had an opportunity of using it in the hospital or elsewhere in any surgical operations. A few days, however, after its discovery, a hernia, which had been strangulated for a few hours, was brought into the Infirmary, and Professor Miller thought it a case demanding operative interference, and one in which chloroform should be tried. But I could not be found in time for the purpose of giving it, and the patient was operated on without any anæsthetic. Professor Miller had only proceeded the length of dividing the skin, when the patient fainted, and died with the operation unfinished. If the chloroform had happened to be used, and this fatal syncope had occurred while the patient was under its action, the whole career of the new anæsthetic would have been at once arrested.

CASE 8.-Within a year or two afterwards, I saw at my own house a child with a laxge abscess in the neck, and I wrote Dr. Pattison, the medical attendant, to the effect that I thought it was sufficiently advanced to be opened. Next day, when about to open the collection of pus, the mother suggested that the child should first have some chloroform exhibited to it. Dr. Pattison had none with him; explained that the walls of the abscess were so thin that the operation would not give much pain; and put his lancet into the purulent swelling. The child immediately fainted and died, without any hæmorrhage or any other complication to account for the fatal syncope.

CASE 9.-In a case belonging to Dr. Gilchrist, of Leith, I saw a surgeon try to treat a sacculated aneurism at the root of the neck by a small quantity of hæmostatic injection. As the operation involved no cutting, no chloroform was used. The patient's respiration speedily became stertorous, and he died in a few minutes.

CASE 10. - In 1853, Dr. Richard Mackenzie was called to see a patient who had shortly before fallen and fractured the radius. Dr. Mackenzie felt his pocket for his chloroform bottle, but found he had it not with him. Anxious not to lose time by sending for it, he forthwith adjusted the displaced ends of the bone, and applied splints and a bandage. A few minutes after leaving the patient's house, Dr. Mackenzie was suddenly recalled, and found the patient dead.

If, in the preceding cases, chloroform had happened to be employed, the fatal results would naturally have been attributed by most minds to the anæsthetic, and not to the operation or the condition of mind or body connected with the operation. Such cases, however, teach us at least that caution is required in our reasoning and inferences, seeing death may occur, and has occurred, in operations without chloroform, and with phenomena quite similar to those ascribed to the action of chloroform. Most of the stronger drugs in the Pharmacopœia, as opium, elaterium, antimony, mercury, \&c., are, proportionally to the number of cases in which they are used in full doses, as fatal as, or more fatal than, chloroform, but they are not so sudden, and hence not so terribly appalling in their dangerous and fatal effects. The proportion of lives lost yearly by the poisonous effects of opium is much greater than that lost by chloroform.* $*$ In 1840, ont of every million living in England and Wales, 24 were poisoned by opium, and 22 by other medicines improperly given to children below the age of five years. (See Seventh Annual Report of the RegistrarGeneral, p. 82). In England and Wales, from 1863-67, there were poisoned, by preparations of opium, 632 individuals; by salts of lead, 242 ; by overdoses of medicine, 52 ; by strychnine, 11 \&c. There were drowned during the same period, while bathing, 707 persons; suffocated by bedclothes,
2332 ; suffocated by overlaying, 682; died from "navel hæmorrhage," 572 , 2332 ; Suffocated by overlaying, 682; died from " navel hæmorrhat
dc. (See Thirtieth Report of the Registrar-General, pp. $176-8$.) 
At our different drug-manufactories in Edinburgh we have upwards of two million doses of chloroform manufactured annually; yet how rarely does a fatal result follow its use. Is there any other common or potent drug which could be given-in full doses-in two millions of instances per annum with greater impunity? But I plead now, as I have ever pleaded, for the greatest care and watchfulness in its exhibition, especially in such large doses as are required in surgical operations.

Edinburgh, February, 1870.

\section{ON M EDICA L EDUCA TION.}

\section{BY F. WM. HEADLAND, M.D., F.R.C.P.,} PHYSICIAN TO CHARING-cross Hospital.

Consiofring that the practiser of the healing art must, if worth anything, be a complex organism of many various endowments, it is apparent that any inquiry into the best method of educating him, of elaborating him for the performance of functions of such importance to mankind, must from first to last be surrounded with considerable difficulty. So that, in giving my opinion somewhat positively on several points concerned in such an inquiry, I do not wish to be understood as presuming to speak authoritatively or ex cathedrâ on the matter, but as subject to the correction of those who have had a wider opportunity of judging of fact and circumstance, and a larger experience of medical teaching than myself.

The education of the medical man, or physician, comprehending under that general term all those who are in any way given to the profession of medicine, if regarded-as it should be-in the widest and most catholic spirit, will be found to present, when compared with the education requisite for other callings, many points of similarity, and some points of difference. The physician, I think, should be viewed, as it were, $a b$ ovo, as destined for that particular calling which is to occupy his lifetime. At the same timeand the same remark may be made with respect to all who are destined to any special vocation-it must be borne in mind that, while nothing is to be subtracted from that system of culture which prepares a man for the higher walks of life, something is to be superadded to it which is peculiar to his case.

The education necessary for a physician may be divided into three periods, which taken together will occups about one-third of the ordinary life of a man. I say nothing more here of the essential requirements, the kind of intellect, the tone of mind, the habit of thought, which alone can fit man for the entry upon such a course of study. I may speak of these in a future paper, when specifying the character which is essential to the medical student. It is enough for me now to suppose that he who is entering on this training is considered by his friends, and considered by himself, to be constitutionally fitted for it. This being premised, and the soil ready for the ploughing and sowing, a certain method of education especially adapted to his wants, and the need of those who may some day require him as a friend and helper, has to be sought out and specified.

The education of the practiser of medicine resolves itself easily into three periods. We have to speak of the early training, of the intermediate training, and of the later training. The age which I shall mention as appropriate for each is given arbitrarily, and only as an approximation to that which will be found convenient in particular cases.

The early training is for the boy of ten years old to the youth of eighteen. Now, of this primary education it may first be laid down that it must at least be that which is considered fitting for a gentleman. In all points of general culture the student must be qualified to take rank rather above than below the average of the cultivated men of his age and period. When we consider the work in store for him, the power and influence which he will be called upon to exercise; that it will be necessary for him to speak to the lower class as one having authority, to mix with the higher class on equal or more than equal terms-as one who knows all that they know, and something besides which it will be to their advantage to recognise,-it is manifest that the higher kind of education must be laid down as a founda- tion on which to erect the superstructure which shall speially mark and characterise the professor of medicine. On this point-that the physician must be, first of all, and before all, a gentleman-I feel so strongly that I must lay it down as an axiom, upon which a great part of my argument will hang. A man who attempts to exercise this calling without any pretence to good breeding or gentility will, from the beginning to the end of his career, be more or less a quack. For skill cannot spring from ignorance, and true earning and science cannot be divorced from general cultivation. And just in proportion as a physician shall fall short of that high standard of refinement at which most of us are aiming, will he find that his chances of advancement and his opportunities of usefulness to his fellow-men will be diminished.

The early training, then, must comprise all that is comprehended under the common term of a "liberal education." It must include a fair knowledge of Latin and Greek, and such an acquaintance with the mathematics as would enable a man to take his degree at Oxford or Cam. bridge. Such knowledge (or nearly as much) is now actually, and I think wisely, demanded in the preliminary examinations of the various boards which give diplomas and confer degrees in Medicine. The medical student, before commencing the study of his art, must be grounded in those branches of knowledge, literary and scientific, which are considered necessary to all well-educated men.

The widest possible curriculum of study would not be too much for the pupil who is designed for a medical career. An acquaintance with other modern languages besides his own-a knowledge, at all events, of the French and German tongues-would be of manifest adrantage to him in the prosecution of his studies. He cannot possibly learn too much, and he must remember that he is about to enter on a pursuit in which those only attain the highest success who know something of everything-in which those who are more or less well read in all the sciences, or who have even the most superficial acquaintance with foreign languages and literature, have an immense advantage over their more ignorant fellows. In regard to the early training, then, the widest possible curriculum should be selected by the student of medicine, endeavouring always, whatever he learns, to learn it well

To this ideal of the early training of a medical student, comprising something more than what would enable hin to take a degree in Arts-a standard which some may think too high, but to which all will, at least, do well to aspire, -something yet must, in my opinion, be added before we can hope to perfect our scheme of medical education. During the three years of what I call the later training, the student finds too often that he has too much to learn. He has to cram into his head about a dozen new sciences, of which he had not previously mastered the rudiments, with a vast amount of unfamiliar lore hanging on the skirts of these sciences, or mixed up with them. By the aid of a retentive memory-one of the most animal of intellectual qualities - he may be enabled to keep hold of all these facts and reasonings for a while, just long enough, perhaps, to qualify him to pass the examinations, which he locks upon as a necessary but almost intolerable evil. Emerging from the presence of the conclave which has dubbed him Doctor or Surgeon, he shakes himself with a delightful feeling of new-found ease, and forgets as soon as may be three-fourths of what he has been taught: the moral of which is threefold-that too much labour, work which ends sometimes in brain fever, often in imbecility, is imposed upon the student during this time; that a period of life at which habits have become inveterate, ideas are formed, and the mind is stored already with almost as much as it can hold, is scarcely fitted for the assimilation of this vast amount of fresh knowledge; and that the true method of education consists in gradual training, inasmuch as what is quickly gained is quickly lost.

These are briefly the matives which induee me to propose an important modification of the system of educating men for this profession. The change which I have to advocate consists in teaching to the boy the rudiments at least of those sciences which are generally reserved for the man of full age. I would include in the early training, instruction in the sciences of Botany, Chemistry, and Natural History; and I would strike them out, as distinct branches of study, from what is commonly known as the medical 